\title{
How Corporate Charitable Giving Reduces the Costs of Formal Controls
}

\author{
Bernhard E. Reichert ${ }^{1} \cdot$ Matthias Sohn ${ }^{2}$
}

Received: 15 August 2019 / Accepted: 31 October 2020 / Published online: 18 January 2021

(c) The Author(s) 2021

\begin{abstract}
Formal control systems are a common instrument to align employees' interests with those of managers and companies. However, research shows that employees perceive formal controls as a sign of distrust and restraint, which can lead to costs of control in the form of lower employee cooperation and effort (e.g., Falk and Kosfeld 2006; Christ 2013). We propose that charitable giving reduces these costs of control. We draw on the halo effect and propose that corporate charitable giving alters employees' perception of and reaction to formal controls. In a laboratory experiment, we find that charitable giving by a company creates a higher level of employee trust in a manager who decides to implement a control and a more positive assessment of formal control. These positive effects of charitable giving lead to lower costs of control compared to the absence of charitable giving. We thereby provide an example of how charitable giving as a corporate social responsibility (CSR) activity yields positive benefits by altering the behavior of internal company stakeholders.
\end{abstract}

Keywords Corporate charitable giving $\cdot$ Halo effect $\cdot$ Costs of controls

\section{Introduction}

Formal control systems are ubiquitous instruments used to address agency problems (Merchant and van der Stede 2017). However, as previous research shows, formal controls produce costs, as employees perceive controls as signals of distrust and restrictions of their free will (e.g., Frey 1993; Falk and Kosfeld 2006; Christ et al. 2008; Schnedler and Vadovic 2011; Ziegelmeyer et al. 2012; Christ 2013; von Siemens 2013). Specifically, controls can crowd out employee preferences for social norms such as fairness, reciprocity, and trust toward a manager implementing formal controls. This crowding-out process decreases employee work effort, motivation, and goodwill toward the manager. These costly adverse reactions impose costs of control (Falk and Kosfeld 2006). We propose that these costs of control are altered when a company engages in charitable giving. Specifically, we propose that employees view controls and

Matthias Sohn

sohn@europa-uni.de

Bernhard E. Reichert

bereichert@vcu.edu

1 Virginia Commonwealth University, Richmond, VA, USA

2 European University Viadrina Frankfurt (Oder), Frankfurt (Oder), Germany the managers implementing them more positively. Consequently, the costs of control are lower compared to the absence of corporate charitable giving.

We base our predictions that charitable giving leads to lower costs of control on the halo effect, which holds that positive assessments of a person or company carry over from one dimension or character trait to another, unrelated dimension (Nisbett and Wilson 1977). We propose that the effect of charitable giving on controls occurs via two halo processes. First, charitable giving prompts the perception of controls to be less negative, which reduces costs of control. Second, charitable giving affects the costs of control by creating a more positive perception of the person implementing formal controls, which results in a more favorable assessment of the formal control the person implements and lower costs of control.

In this study, we build on a research design used by Falk and Kosfeld (2006). ${ }^{1}$ We assign participants to the role of either employee or manager. Participants interact for 20 rounds, rematching with a different participant in every round. Although we rematch participants, they remain in their role as either employee or manager. ${ }^{2}$ The employee receives an endowment of 120 points in each round, while

\footnotetext{
${ }^{1}$ We rely on the design of this study because it is the first study to document costs of control in a laboratory setting.

2 We use neutral terms such as Participant A and Participant B in the instructions to participants.
} 
the manager is not given any points. The employee decides to send points to the manager as a proxy for employee effort. We elicit employee point-transfer decisions for two cases, namely, when the manager implements a control system and when the manager does not implement a control system. If the manager decides to implement a control system, then the control system requires a minimum transfer of five points. Any points sent will be tripled. The manager receives twothirds of the tripled point score, and the remaining one-third goes to either a charity or an unnamed third party. ${ }^{3}$ Participants receive no feedback, either on the implementation of control systems or on point-transfer decisions, until all participant interactions are completed.

We manipulate two factors: one factor within-subjects and one factor between-subjects. The within-subjects manipulation is the control system manipulation as either the manager implements a control or does not. The second manipulation, the between-subjects manipulation, is the charity manipulation. In one condition, we specify that the recipient of onethird of the tripled points will be the Philadelphia Animal Welfare Society (PAWS), a non-profit charity whose goal is to find homes for animals. ${ }^{4}$ It operates low-cost animal hospitals and no-kill shelters. In the other condition, we do not specify the recipient of the transfers. At the end of 20 rounds, we measure employees' perceived trustworthiness of the manager and their perception of the control system.

Consistent with Falk and Kosfeld (2006), we find that in the absence of corporate charitable giving, employees transfer fewer points when a manager implements a control system than when a manager does not. In comparison, when the company engages in charitable giving, employees transfer comparable amounts of points to the manager when the manager implements a control system compared to when the manager does not. These results indicate that the costs of control are lower when a company engages in charitable giving. ${ }^{5}$

\footnotetext{
${ }^{3}$ All points are converted to cash at the end of each session and paid to the manager participants, the employee participants, and either PAWS or the unspecified third-party recipient.

4 The decision to contribute to a charity is made by the company (i.e., exogenously imposed), while the decision to implement controls is made by the manager (i.e., endogenously imposed).

5 We find that the difference in points transferred from the employee to the manager when the manager implements a control compared to when the manager does not implement a control is statistically significant in the absence of charitable giving, but not statistically significant when the company engages in charitable giving. However, the mean level of point giving is higher when controls are absent compared to when controls are present in the charitable giving condition. To be cautious, we frame our results throughout the paper as a reduction of the costs of control rather than an elimination. The reason for our cautious approach is that as with any laboratory research, we rely on a relatively small sample size compared to real life. In companies, given the ubiquitous nature of control, the difference in expressed employee goodwill could be material when the company engages in
}

We test a path analysis model based on the halo effects that we propose. The results are consistent with the proposed halo effects. Charitable giving leads to a more positive assessment of the implemented formal control, which results in lower costs of control. In addition, we find an indirect effect of charitable giving on the costs of control exerted through a higher perceived trustworthiness of the manager who makes the control implementation decision and a more positive assessment of the control system.

Our findings make several contributions to the literature on control systems and on charitable giving. To our knowledge, this study is the first to show that employee perceptions of control and negative reactions to control can be altered by CSR practices expressed through charitable giving. The positive effect of corporate giving on the costs of control has important implications for the applicability of prior findings that demonstrate costs of control (e.g., Falk and Kosfeld 2006; Christ 2013). Our results suggest that the overall purpose of a company matters. Negative employee reactions to formal controls in practice might be reduced by emphasizing how the company serves a beneficial purpose for society, such as being charitable.

Second, we contribute to the literature on how CSR practices, particularly philanthropic behavior, strengthen stakeholder relations. ${ }^{6}$ Most CSR research focuses on the external benefits of such activities, and research on how CSR behavior affects internal stakeholders is relatively scarce (e.g., Peloza and Shang 2011; Balakrishnan, Sprinkle, and Williamson 2011; Block et al. 2017). Our study contributes to a growing body of research examining how CSR activities increase employee trust in the organization and thus lead to beneficial employee behaviors, such as organizational citizenship behavior or lower turnover intentions (e.g., Aguilera et al. 2007; Hansen et al. 2011). We enrich these findings by showing an additional benefit of charitable giving, namely, fewer negative employee reactions to formal control. Our contribution answers the call for more experimental research on the benefits of different CSR practices (e.g., charitable giving) in settings in which archival data are unavailable (Moser and Martin 2012; Huang and Watson 2015).

Lastly, we contribute to the accounting literature on the effects of charitable giving. Balakrishnan et al. (2011) show

\footnotetext{
Footnote 5 (continued)

charitable giving, though, importantly, smaller than in the absence of corporate giving.

${ }^{6}$ For example, corporate giving increases consumers' product awareness and perception, thus increasing sales and market shares (Chernev and Blair 2015; Sen and Bhattacharya 2001), and helps attract more qualified employees (Greening and Turban 2000). Additionally, investors react positively to companies engaging in CSR activities (Martin and Moser 2016), which reduces firms' cost of capital (El Ghoul et al. 2011).
} 
that employees exert a costlier effort as charitable giving by a manager increases. In this situation, employers can use charitable giving strategically to induce employees to respond favorably to different levels of employer charitable giving. We extend Balakrishnan et al. (2011) by showing that charitable giving affects employees' perception of managers and management accounting instruments even when the manager does not make the decision to engage in charitable giving. Charitable giving is exogenously imposed in our setting and nevertheless spills over to managers by generating a more positive assessment of the manager's actions. ${ }^{7}$

The remainder of the paper proceeds as follows. In part 2, we review previous research on the costs of control and the halo effect and develop our hypotheses. In part 3, we provide information on our instrument and the data collection process. In part 4, we present our results, and part 5 concludes with a discussion of our findings.

\section{Hypotheses}

This study examines the effect of charitable giving by a company on employee perception of the trustworthiness of the manager making the decision to implement a control system, employee perception of the control system, and the costs of control. The costs of control refer to a "crowding out" of natural goodwill toward interaction partners in response to the interaction partner's implementation of controls. Research shows that individuals engage in more selfish, opportunistic behavior in response to the implementation of controls (Frey 1993; Falk and Kosfeld 2006). This behavior results from employees perceiving formal controls as signaling that the person who implements a control distrusts them and deliberately aims to restrict their freedom. Recent research investigates contextual factors that moderate this relationship between the implementation of formal control and employee reactions to control (Coletti et al. 2005; Christ et al. 2012; Christ 2013). For example, Coletti et al. (2005) show that when individuals observe positive consequences of formal control by control inducing cooperation, controls can increase trust among individuals. In a similar vein, Christ et al. (2012) find that positively framed control in the form of bonus contracts creates a more trusting environment and thus increases employees' general trust and goodwill toward the individual implementing the contract. In contrast,

\footnotetext{
7 This contribution is noteworthy because corporate charitable giving decisions are commonly made by higher-level managers rather than by low-level managers because centrally administering charitable giving ensures that charities have the necessary governance structures. Such giving differs from corporate charitable matching programs in which companies contribute to individual employee charitable contributions.
}

negatively framed contracts (penalty contracts) lower trust and goodwill toward the interaction partner. Christ (2013) finds that employees' negative reactions (distrust and lower effort) toward the manager are only observable when control is endogenously implemented by the manager and diminish when control is exogenously implemented. This finding underpins the idea that management's intentions greatly affect employees' beliefs and behavior (Falk and Kosfeld 2006; Kuang and Moser 2009).

We extend this research on employee reactions to formal control by focusing on the implications of research on CSR and charitable giving. Specifically, we explore whether employees are more accepting of formal control when a company engages in charitable giving. This research also extends work on charitable giving in accounting by Balakrishnan et al. (2011), who find a positive link between an employer's engagement in charitable giving and employee efforts that benefit the employer when employers can use charitable giving as a strategic signal.

We base our predictions of the effect of charitable giving on the costs of control on the halo effect. The halo effect refers to individuals transferring positive feelings about one characteristic of a person or object to another, unrelated characteristic of the to-be-judged person or object (Thorndike 1920; Nisbett and Wilson 1977). For example, Dion et al. (1972) find that individuals believe attractive people possess more socially desirable personality traits (e.g., altruism and trustworthiness) compared to unattractive people. The halo effect holds for an individual's character traits and applies to objects, companies, or brands. Consumer research observes the presence of a health halo in food choices; more specifically, individuals perceived fast food meals described as "healthy" (Subway) as having up to 35 percent fewer calories compared to an identical fast food meal without such a health claim (McDonald's) (Chandon and Wansink 2007).

The halo effect has also been demonstrated in accounting research, particularly in research on auditing and performance evaluation. Auditing research suggests that managers evaluate memos written by outstanding seniors more favorably than they do those written by average seniors (Tan and Jamal 2001). O'Donnell and Schultz (2005) observe that auditors who develop favorable strategic risk assessments are less likely to adjust account-level risk assessments for inconsistent fluctuation. In a performance evaluation setting, Duarte et al. (1994) find that the employee performance in high-quality, trustful leader-member relationships is rated highly, regardless of the employees' objective performance. In a similar vein, Bol and Smith (2011) show that superiors' subjective evaluations of their subordinates' performance are significantly biased toward the subordinates' objective performance. The objective performance serves as a halo 
that spills over to superiors' subjective evaluations of the to-be-judged employees.

In our setting, we propose halo effects in two processes. First, we propose that the positive image of corporate giving under the charity condition serves as a halo for employees when they evaluate the control system. This effect leads employees to perceive controls less negatively when the company engages in corporate giving. A more positive perception of the control system leads to lower costs of control. This proposed effect is consistent with marketing research showing that acts of corporate charitable giving carry over to product perceptions. For example, the products of companies engaged in corporate giving are perceived to be of higher quality (Chernev and Blair 2015).

Second, we propose an indirect effect of charitable giving on the costs of control that works through employees' perception of the manager who decides to implement a formal control and the perception of the manager's actions. We base these predictions on experimental economics research that shows a positive correlation between altruistic behavior and trustworthiness (Barclay 2004; Ashraf et al. 2006; Chaudhuri and Gangadharan 2007; Albert et al. 2007; Fehrler and Przepiorka 2013). For example, Fehrler and Przepiorka (2013) find that charitable giving is correlated with the perceived trustworthiness of the donor and that a charitable donation increases an observing agent's trust in the donor. Similarly, research on CSR shows that firm engagement in CSR practices increases employee trust in the organization, which results in greater employee commitment and an increased employee willingness to reciprocate with the company (e.g., Aguilera et al. 2007; Rodrigo and Arenas 2008; Hansen et al. 2011; De Roeck and Maon 2018).

Based on these findings, we propose that a manager who makes the control implementation decision is perceived to be more trustworthy when the company engages in charitable giving compared to when the company does not engage in corporate giving. We further propose that this positive assessment of the manager is reflected in how employees perceive the manager's control implementation decision. Specifically, we propose that a more positive perception of the manager generates a more positive employee perception of any controls implemented by the manager. Lastly, this more positive perception of formal controls leads to lower costs of control. ${ }^{8}$

\footnotetext{
${ }^{8}$ Notably, the halo effects we suggest are different from the halo effect often used in the literature. In the literature, halo effects often suggest that positive aspects of a person or object spill over to other aspects of that same person or object. However, we propose that the positive aspect of the company (charitable giving) cascades down to the company manager (trust in the manager) and the perception of the control system. Such a halo effect is consistent with some examples from the marketing literature we cite.
}

Based on the arguments presented, we hypothesize the following:

H1 Charitable giving by a company leads to lower costs of control when controls are present compared to a company not engaged in charitable giving.

This overall effect of charitable giving on the costs of control results from the effect of charitable giving on the perceived trustworthiness of the person implementing the controls and the perception of the control system, as follows:

H2 Charitable giving by a company leads to less negative perceptions of a control system compared to a control system in a company not engaged in charitable giving.

H3 Charitable giving by a company leads to higher perceived trustworthiness of a manager who implements a control system compared to a manager in a company not engaged in charitable giving.

\section{Method}

\section{Experimental Task}

We conduct a laboratory experiment to test our hypotheses. Our experimental design is based on Falk and Kosfeld (2006). ${ }^{9}$ The participants in our study played a version of the standard dictator game. We randomly assigned participants to the role of either employee (identified in the experimental materials as "Participant A") or manager (identified in the experimental materials as "Participant B"). Employee participants were given 120 points, while manager participants received 0 points at the beginning of each round. Employees could send points to managers. We elicited these pointtransfer decisions by employees as our main dependent variable. Employees and managers interacted for 20 rounds and were rematched with another interaction partner every round while remaining in their respective roles. After the completion of round 20, we elicited process information from each participant using a post-experimental questionnaire.

\footnotetext{
9 Although we retain the main features and language in the instructions of Falk and Kosfeld (2006) when possible, the design of our study differs in several ways. For example, in Falk and Kosfeld (2006), participants interact for one round; the manager and employee participants are the only recipients affected by the transaction, and three levels of control are examined. In comparison, in our study, participants interact for 20 rounds; compensation is based on one randomly determined round, and a third party in the form of an unknown entity or PAWS is affected by point-transfer decisions. Aside from these differences, we use the same wording in the instructions as the original study.
} 
We manipulated two factors in a $2 \times 2$ mixed experimental design: (1) control system presence (control) versus the absence of a control system (non-control) and (2) charity donation (charity) versus an unspecified third-party recipient (non-charity). We administered the first manipulation, i.e., the control system presence manipulation, as a withinparticipants manipulation, which mirrors the experimental setup of Falk and Kosfeld (2006). The second manipulation, our charity manipulation, was administered between participants.

\section{Control Presence Versus Non-control Manipulation}

We elicit employee point transfers for two cases: the case in which the manager has implemented a minimum-transfer requirement of five points, which proxies for a control system, and the case in which such a minimum-transfer requirement is absent (Fischbacher et al. 2001; Falk and Kosfeld 2006; Christ 2013). Managers could decide anew in each round whether to implement a control system. Employees never learned the manager's control system implementation decision. ${ }^{10}$

\section{Charity Versus Unspecified Third Recipient Manipulation}

Consistent with a dictator game, the employee could decide whether to transfer points to the manager. Any points sent were tripled. ${ }^{11}$ The manager would receive two-thirds of the points. ${ }^{12}$ One-third of the points would go to an unspecified third party or to PAWS. ${ }^{13}$ In the non-charity condition, we did not provide any information about the recipient of the

\footnotetext{
${ }^{10}$ We did not provide feedback at the end of each round to keep the decisions between rounds comparable and to use as simple a design as possible. Christ (2013) uses a setting similar to Falk and Kosfeld (2006), but with 20 rounds. For the first 10 rounds, participants do not receive any feedback about employer decisions, while they receive feedback in the second 10 rounds. The study did not find any impact of feedback on the strength of negative employee reaction toward control.

11 We do not use a non-recipient condition on purpose, as including such a condition would lead to payoff parameters that are different between cells, which would confound the payoff size with the experimental treatments.

12 Falk and Kosfeld (2006) endow the sender with 120 points and the receiver with zero points. Any points transferred are doubled. We triple every point transferred and dedicate one-third of the points to a third party. Although transactions in our setting create more wealth because we triple any points transferred, we use the same relative point split and payoff function between the employee and manager that Falk and Kosfeld (2006) use in their study.

13 This point transfer is automatic. To engage in charitable giving or transfer to an unknown third party is not a decision that the managerparticipant made.
}

one-third of the increased point score. ${ }^{14}$ In the instructions to participants, we refer to the recipient as an "unknown third party." 15 The payoff functions are thus given by $\pi_{\mathrm{m}}=2 \times$ for the manager, $\pi_{\mathrm{e}}=120-x$ for the employee, and $\pi_{\mathrm{p}}=x$ for PAWS (or the unknown third party). ${ }^{16}$ The payout functions for the manager and the employee are identical to those in Falk and Kosfeld (2006).

In the instructions for the charity condition, we described PAWS as "a charitable organization that rescues and shelters animals." We further explained that "the Philadelphia Animal Welfare Society is working to make Philadelphia a city where every healthy pet is guaranteed a home." PAWS is the city's largest rescue partner. In the instructions to participants, we described PAWS as operating two high-volume, low-cost clinics that serve pet owners; it also operates three no-kill shelters and a foster care network that aims to find homes for animals.

\section{Experimental Procedures}

One hundred and two undergraduate students participated in our laboratory experiment. ${ }^{17}$ Participants were randomly matched to 51 employee and manager dyads. We collected information on the participants' background, such as their country of origin, gender, and age. We found no statistically significant difference among cells for participant attributes (all $p$ values $>0.100$ ).

At the beginning of the session, the participants learned of their role assignment as either employee or manager and received the study instructions in electronic form using z-Tree software (Fischbacher 2007). The use of z-Tree for both communication and task participation ensured participant anonymity. Participants read the instructions at their computer terminals at their own pace. At the end of the instructions, participants answered a true-false quiz to ensure they understood the task and payout scheme. Any question answered incorrectly led to the display of additional information describing why the previous answer choice was

\footnotetext{
${ }^{14}$ We intentionally did not provide participants a choice of charities, which on average is likely to have created greater participant identification with the charitable cause. Providing a charitable cause allows us to observe variance in the level of identification with the charity and in turn the effect of the level of identification with the charity on the costs of formal control.

15 We donated these funds to "FeedMore Inc.," which describes itself as central Virginia's core hunger relief organization. We used the same conversion factor for donated funds that we used for participant compensation.

${ }^{16}$ For funds paid to PAWS and the unknown third party, we used the same point-to-US dollar conversion factor that we used for payments to participants.

17 We obtained IRB approval for our study.
} 
incorrect. Participants had to repeat incorrectly answered questions until they answered them correctly.

After successfully answering the understanding- and manipulation-check questions, participants started the main part of the experiment. Employees made two point-transfer decisions on one screen. One transfer decision was for the case in which the manager implemented a control system, while the other point-transfer decision was for the case in which the manager did not implement a control system. If a control system was implemented, the minimum transfer to the manager would be five points, which would limit the employee's choice to a point range between five points and 120 points. We intentionally picked a minimum pointtransfer requirement of five points. Falk and Korsfeld (2006) test three minimum-transfer requirements in their study: 5 points, 10 points, and 20 points. For these three levels, their study finds the highest difference in employee point transfer when a control is present and when it is absent, i.e., the highest costs of control, under the five-point-transfer requirement condition.

While the employees made their transfer decisions, managers decided to implement a control system. We asked managers whether they wanted to force the employee to transfer at least five points. Once employees and managers made their choice, the round ended. We did not provide feedback. A new round started immediately after both parties made their choices, with both parties being matched to another participant (see Fig. 1). Participants engaged in the task for 20 rounds.

Upon the completion of all 20 rounds, we asked participants several questions. Specifically, we asked participants in the employee role the extent to which they perceived their interaction partner to be trustworthy. ${ }^{18}$ We measured employee perception of the manager by using an aggregate measure based on questions from the leadership-exchange literature and the trust literature. We asked several questions and conducted a factor analysis with varimax rotation to identify an instrument. The instrument included questions such as "I have complete faith in the integrity of Participants B" or "I perceive Participants B to be individuals who can be trusted to serve the interest of others rather than themselves" (see Table 6 for all items). All questions were asked

\footnotetext{
${ }^{18}$ Based on extant research showing that perceived distrust is a main driver for employees' negative responses to formal controls, we measured the perceived trustworthiness of the interaction partner and the perception of the control system (Falk and Kosfeld 2006; Christ 2013). In addition, we acknowledge that our questions about trustworthiness refer to a generic interaction partner, as our participants engage for 20 rounds with rematching. Because participants did not receive feedback or any information about the interaction partner, we deem this design choice justifiable. This design choice works against us finding results. Nevertheless, we find differences in perceived trust between conditions.
}

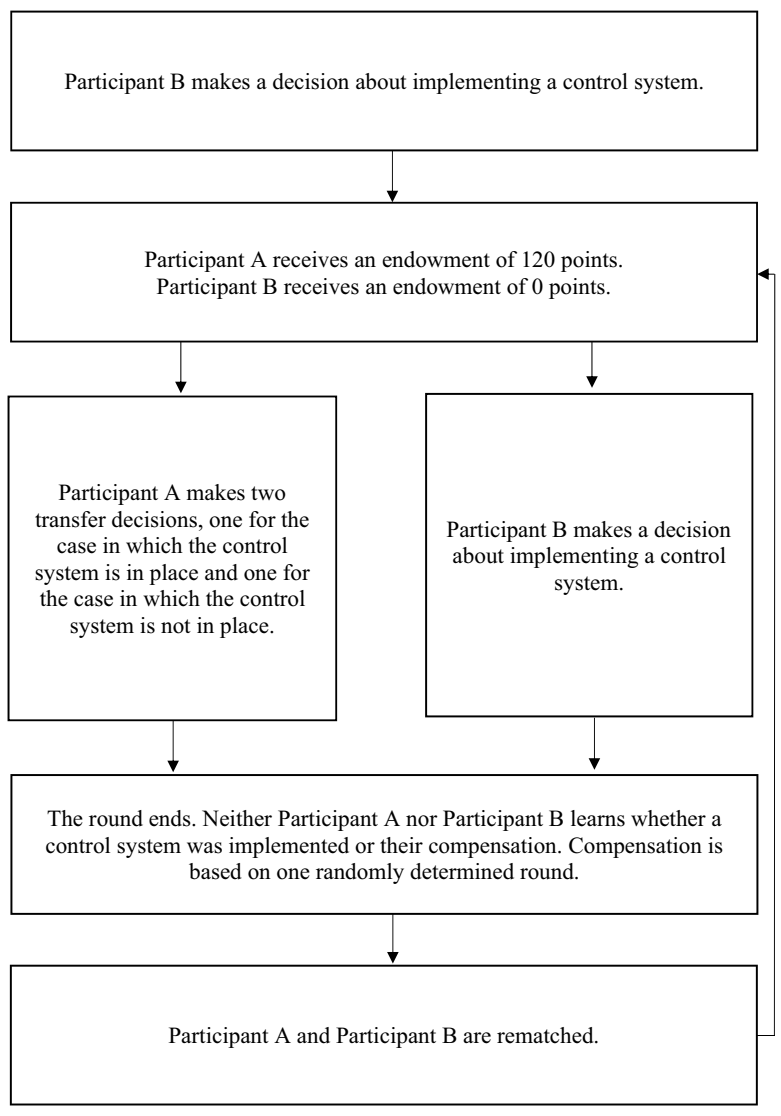

Fig. 1 Flow of experiment

using 7-point or 11-point scales ranging from "not at all" to "extremely" $(\alpha=0.662)$.

In addition, we elicited the employee participants' perception of the control system. Again, we conducted a factor analysis with varimax rotation to identify a measure. We asked participants questions such as "To what extent do you perceive the minimum-transfer requirement as a sign of distrust?" or "To what extent did you consider the minimumtransfer requirement as a restriction on your free will?" (see Table 5 for all items). Participants rated their agreement with these statements on 11-point scales from "not at all" to "a great deal" $(\alpha=0.748)$.

We also asked employee participants about their perception of the charity or third party. Specifically, we asked three types of questions that measured the participants' willingness to support the charity economically, their respect for the charity's cause, and the level of consideration they gave to the charity when making transfer decisions. We measured all items on an 11-point scale, e.g., "Would you donate money to the Philadelphia Animal Welfare Society/Unknown Third Party in the future?" and "To what extent do you identify with the Philadelphia Animal Welfare Society/Unknown Third Party?" (see Table 1 for all items). We conducted a factor analysis, which identified three factors for our group 
of questions. The first factor measures economic identification with PAWS/third party $(\alpha=0.964)$. The second factor measures emotional identification $(\alpha=0.856)$, while the third factor measures the consideration of transfers to the third party when making the transfer decision $(\alpha=0.859)$. The employee identification with the charity/third-party measure serves two important purposes in our research. First, it serves as a manipulation check for the charity condition, as our proposed process model only works when participants perceive the charity's cause as good. Hence, we omitted data from five participants in the employee role in the charitable giving condition from our analysis because those participants indicated that they did not identify with PAWS at all. ${ }^{19}$ Second, this measure allows us to examine whether the strength of identification affects our main results.

Finally, participants in the manager role were asked to briefly describe their reasons for implementing a minimumtransfer requirement of five points. We elicited the social value orientation (SVO), moral identity (MI), and biographical data from both types of participants. To determine SVO, we used an instrument from Van Lange et al. (1997), which required participants to pick one of three allocation choices between two parties for nine sets of outcomes $(\alpha=0.938)$. To determine MI, we used a scale from Aquino and Reed (2002). These personal values of participants in the charity group did not differ from those in the non-charity group.

\section{Participant Compensation}

Participant compensation was based on a fixed component of $\$ 5$, which was paid to every participant, regardless of points earned in the study, plus points earned in one randomly determined round. ${ }^{20}$ Total points accumulated in one randomly chosen round were converted to compensation paid in US dollars at a rate of $\$ 0.075$ per point.

\footnotetext{
19 We conduct our main analysis of the effect of charitable giving on point transfers with all participants as a robustness check. Specifically, we conduct an ANCOVA with the participant age as the covariate, with a point-transfer decision in the presence of controls versus the absence of control as the within manipulation and charitable giving as the between-participant manipulation. We find a significant interaction term $(F$ value $=2.194, p$ value $=0.073)$. We conduct the same analysis without the five participants, and we again find a significant interaction term $(F$ value $=2.770, p$ value $=0.052)$. Hence, we receive qualitatively comparable results when we include those five participants. However, our process model is not supported when we include these five participants. For this reason and to be consistent with the treatment of participants that fail manipulation checks in the literature, we omitted these five participants from our analysis.

${ }^{20}$ In comparison, Falk and Kosfeld (2006) pay a fixed compensation of CHF 10 and convert points earned in the study based on CHF 0.20 per point.
}

\section{Results}

\section{Validating our Setting}

To validate our setting, we examine two effects: (1) the effectiveness of our charity manipulation and (2) the costs of control when the company does not engage in charitable giving.

First, to determine the effectiveness of the charity manipulation, we examine the differences in perception between transfers to an unspecified third-party recipient and the charity (PAWS). Table 1, Panel A, provides descriptive statistics for economic identification, emotional identification, and consideration of contributing resources to the recipient, with all means being higher for PAWS than for when the recipient is unspecified. We conduct pairwise comparisons for each factor, comparing the non-charity condition to the charity condition and apply non-parametric tests. We find that participants' economic identification $(\mathrm{Z}$-score $=2.449$, $p$ value $=0.007)$, emotional identification $(Z$-score $=3.659$, $p$ value $<0.001$ ), and consideration of contributing resources $(\mathrm{Z}$-score $=1.817, p$ value $=0.036)$ are statistically significantly lower when the third-party recipient is unspecified compared to when PAWS is the recipient (see Table 1, Panels $\mathrm{B}, \mathrm{C}$, and D). This confirms that our charity manipulation instilled a stronger emotional bond for employees when the charity was the recipient than when the third-party recipient was unspecified.

Second, to determine the presence of costs of control, we compare point transfers from employees to managers when a control is present to when it is absent in the non-charity condition. Table 2, Panel A, provides descriptive statistics of transfers from the employee to the manager when control systems are implemented and when controls are not implemented. Table 2, Panel B, compares the point transfers when the manager employs a control system to the point transfers when the manager does not implement a control system in the non-charity condition. We calculate a Wilcoxon signedrank test to compare the point transfers. ${ }^{21}$ We find that the difference is statistically significant ( $\mathrm{Z}$-score $=2.051, p$ value $=0.020) .{ }^{22}$ Thus, we find a result comparable to that

\footnotetext{
${ }^{21}$ We perform non-parametric Wilcoxon signed-rank tests, where appropriate, to make the study consistent with prior research on the costs of control (Falk and Kosfeld 2006). However, we also calculate a simple $t$ test, which led to qualitatively identical results.

${ }^{22}$ Consistent with the directional predictions, we provide one-tailed $p$ values where we have directional predictions. Otherwise, all $p$ values are two-tailed. We provide directional interaction terms throughout the results section consistent with Kachelmeier, Thornock, and Williamson (2016). Kachelmeier et al. (2016) state that "[...] a onetailed $p$ value is appropriate for testing directional predictions of $2 \times 2$ interactions that can only exhibit two possible directions" (McNeil, Newman, and Kelly 1996, 137-39).
} 
Table 1 Perception of third-party recipient

Panel A: Means (standard deviations) of employee perception of recipient ${ }^{\mathrm{a}}$

\begin{tabular}{|c|c|c|}
\hline & $\begin{array}{l}\text { Unspeci- } \\
\text { fied } \\
\text { recipient }\end{array}$ & Charity recipient \\
\hline Would you donate money to the Philadelphia Animal Welfare Society/Unknown Third Party in the future? ${ }^{\mathrm{b}}$ & $\begin{array}{l}4.18 \\
(2.95)\end{array}$ & $\begin{array}{l}6.17 \\
(2.94)\end{array}$ \\
\hline $\begin{array}{l}\text { Would you encourage others to donate money to the Philadelphia Animal Welfare Society/Unknown Third } \\
\text { Party? }\end{array}$ & $\begin{array}{l}4.14 \\
(2.98)\end{array}$ & $\begin{array}{l}6.50 \\
(2.57)\end{array}$ \\
\hline Economic Identification Score $(\alpha=0.964)$ & $\begin{array}{l}8.32 \\
(5.84)\end{array}$ & $\begin{array}{l}12.67 \\
(5.39)\end{array}$ \\
\hline To what extent do you identify with the Philadelphia Animal Welfare Society/Unknown Third Party? ${ }^{\mathrm{b}}$ & $\begin{array}{l}2.64 \\
(2.15)\end{array}$ & $\begin{array}{l}4.58 \\
(2.96)\end{array}$ \\
\hline Do you have a positive perception of the Philadelphia Animal Welfare Society/Unknown Third Party? ${ }^{\mathrm{b}}$ & $\begin{array}{l}4.59 \\
(1.76)\end{array}$ & $\begin{array}{l}7.50 \\
(2.27)\end{array}$ \\
\hline $\begin{array}{l}\text { To what extent do you think the Philadelphia Animal Welfare Society/Unknown Third Party uses the funds for a } \\
\text { socially beneficial purpose? }\end{array}$ & $\begin{array}{l}4.14 \\
(2.46)\end{array}$ & $\begin{array}{l}7.04 \\
(2.51)\end{array}$ \\
\hline Emotional Identification Score $(\alpha=0.856)$ & $\begin{array}{l}11.37 \\
(4.98)\end{array}$ & $\begin{array}{l}19.12 \\
(6.91)\end{array}$ \\
\hline $\begin{array}{l}\text { To what extent did you consider the effect of your point-transfer decision on the Philadelphia Animal Welfare } \\
\text { Society/Unknown Third Party when making your transfer decision and when a minimum-transfer requirement } \\
\text { was in place? }^{\text {b }}\end{array}$ & $\begin{array}{l}3.41 \\
(3.13)\end{array}$ & $\begin{array}{l}5.54 \\
(2.93)\end{array}$ \\
\hline $\begin{array}{l}\text { To what extent did you consider the effect of your point-transfer decision on the Philadelphia Animal Welfare } \\
\text { Society/Unknown Third Party when making your transfer decision and when no minimum-transfer requirement } \\
\text { was in place? }\end{array}$ & $\begin{array}{l}4.32 \\
(3.52)\end{array}$ & $\begin{array}{l}5.67 \\
(2.94)\end{array}$ \\
\hline Third-Party Consideration Score $(\alpha=0.859)$ & $\begin{array}{l}7.73 \\
(6.07)\end{array}$ & $\begin{array}{l}11.21 \\
(5.63)\end{array}$ \\
\hline
\end{tabular}

Panel B: Mann-Whitney test on "economic identification score"

\begin{tabular}{|c|c|c|c|}
\hline Comparison & d.f & Z-Score & $p$ value $^{\mathrm{c}}$ \\
\hline Charity recipient versus unknown recipient & 1 & 2.449 & 0.007 \\
\hline \multicolumn{4}{|c|}{ Panel C: Mann-Whitney test on "emotional identification score" } \\
\hline Comparison & d.f & Z-Score & $p$ value $^{\mathrm{c}}$ \\
\hline Charity recipient versus unknown recipient & 1 & 3.659 & $<0.001$ \\
\hline \multicolumn{4}{|c|}{ Panel D: Mann-Whitney test on "third-party consideration score" } \\
\hline Comparison & d.f & Z-Score & $p$ value $^{\mathrm{c}}$ \\
\hline Charity recipient versus unknown recipient & 1 & 1.817 & 0.036 \\
\hline
\end{tabular}

${ }^{a}$ The dependent variables are the three different dimensions of employees' perception of the recipient (PAWS/unknown third party)

${ }^{\mathrm{b}}$ Measured on a 1 to 11 scale

${ }^{\mathrm{c}}$ We report one-tailed $p$ values

of Falk and Kosfeld (2006) when the transfer decision affects an unspecified third party.

\section{Effect of Control Systems and Charitable Giving on the Costs of Control (H1)}

Hypothesis 1 proposes that employees react differently to the implementation of formal controls when the company engages in charitable giving compared to when the company does not. Table 2, Panel A provides descriptive statistics for the average points transferred across the 20 rounds from employees to managers (for a graphical expression, see Fig. 2). ${ }^{23}$ Employees in the charity condition react to the

\footnotetext{
${ }^{23}$ Using 20 rounds offers the advantage of examining behavioral changes over time, which is particularly important for a concept that could be driven by emotions or transient feelings. However, using multiple rounds could come at a cost because of demand effects or fatigue. To alleviate concerns that such effects could bias our results, we analyze the costs of control for round 1 separately and analyze changes in the costs of control between the first half and the second half. For round 1, we conduct an ANOVA with charitable contributions as the between-participant factor, formal control as the within-participant factor, and point transfer as the dependent vari-
} 
Table 2 Point transfer decision

Panel A: Mean (standard deviation) of points transferred from employees to managers (averages from rounds 1 to 20) ${ }^{\mathrm{a}}$

\begin{tabular}{|c|c|c|}
\hline & $\begin{array}{l}\text { Unspecified recipient } \\
n=22\end{array}$ & $\begin{array}{l}\text { Charity recipient } \\
n=24\end{array}$ \\
\hline Non-control & $\begin{array}{l}25.13 \\
(25.42)\end{array}$ & $\begin{array}{l}23.92 \\
(15.53)\end{array}$ \\
\hline Control & $\begin{array}{l}17.41 \\
(18.44)\end{array}$ & $\begin{array}{l}21.35 \\
(15.53)\end{array}$ \\
\hline Difference between control and non-control & $\begin{array}{l}7.72 \\
(14.52)\end{array}$ & $\begin{array}{l}2.57 \\
(9.46)\end{array}$ \\
\hline
\end{tabular}

Panel B: Wilcoxon Signed-Rank test on the points transferred from employees to managers (averages from rounds 1 to 20)

\begin{tabular}{llll}
\hline Comparison & d.f & Z-Score & $p$ value \\
\hline Control versus non-control unspecified recipient & 1 & 2.051 & 0.020 \\
\hline
\end{tabular}

${ }^{\text {a }}$ The dependent variable is the number of points sent by the employee to the manager

${ }^{\mathrm{b}}$ We report one-tailed $p$ values

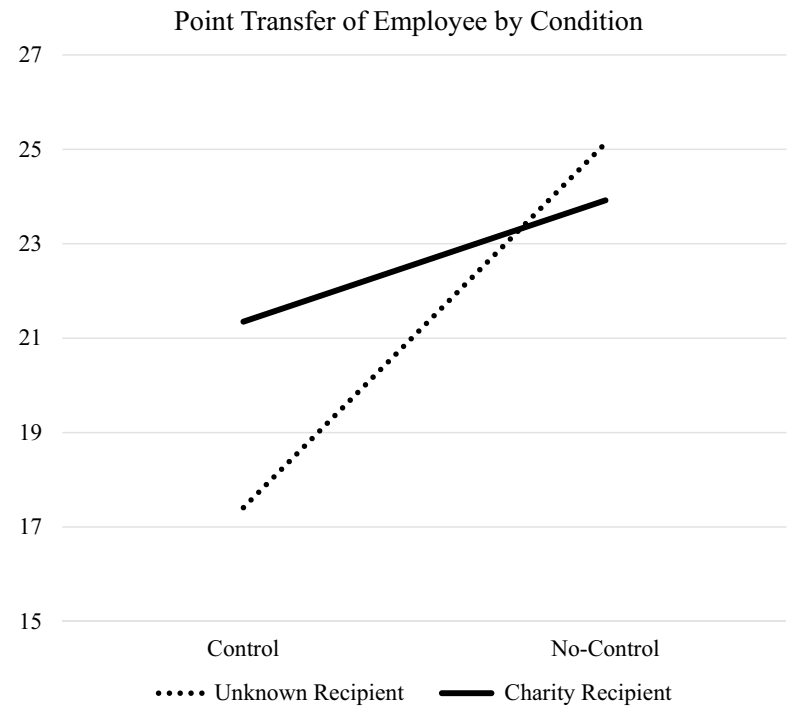

Fig. 2 Point transfer from employee to manager (averages from rounds 1 to 20 )

\section{Footnote 23 (continued)}

able. We find a statistically significant interaction $(F$ value $=2.863$, $p$ value $=0.049$ ). In addition, we compare point transfers for the first 10 rounds with point transfers for the second 10 rounds. Point transfers differ neither in the non-charity condition (Z-score $=0.806$, $p$ value $=0.420)$ nor in the charity condition $(\mathrm{Z}$-score $=0.251, p$ value $=0.802$ ). Finally, we calculate a lagged variable whereby we take point transfers from a round and subtract the point transfers from the previous round. The mean of this measure across all 19 lagged variables is 0.055 for the non-charity condition and -0.351 for the charity condition. We calculate an ANOVA with the 19 lagged variables as the within-participant manipulation and charitable giving as the between-participant manipulation. Charitable giving $(F$ value $=1.048$, $p$ value $=0.312)$, round $(F$ value $=0.973, p$ value $=0.403)$, and the interaction between round and charitable giving $(F$ value $=1.803, p$ value $=0.155$ ) are not statistically significant. These findings indicate that our results are not biased by demand effects or fatigue effects. introduction of a control system with a smaller reduction in points transferred to managers (23.92 to 21.35) compared to when the third-party recipient is unspecified (25.13 to 17.41).

Table 3, Panel A tests the joint effect of charitable giving and the presence (or absence) of formal control on the differences in points transferred by employees. We conduct a repeated-measures ANOVA with the presence of formal control as the within-subjects factor, charitable giving as the between-subjects factor, and participants' point transfers as the dependent variable. Table 3, Panel A, shows that the interaction between charitable giving and the presence of formal control is statistically significant $(F$ value $=2.061, p$ value $=0.079) .{ }^{24}$ We conduct pairwise comparisons of transfers from employees to managers when control is present compared to when the manager does not introduce control. We calculate these comparisons separately for the charitable giving condition and the non-charitable giving condition. The difference in point transfers in the non-charitable giving condition is statistically significant (Z-score $=2.051$,

\footnotetext{
${ }^{24}$ To validate these results, we also run a regression with a control system, charitable giving, and the interaction of the two as independent variables and the transfer decision as the dependent variable. Additionally, in the regression we do not use the average transfers across the 20 rounds as the dependent variable but include "round" and "participant" as fixed effects in the regression. We furthermore control for participants' age. The regression results support the ANOVA results, as we also find a significant main effect for control systems $(t$ value $=-6.31, p$ value $<0.001)$ and a significant interaction $(t$ value $=2.93, p$ value $=0.009)$ when controlling for roundfixed effects and participant fixed-effects. Moreover, the regression results hold for the full sample, i.e., including the five participants we excluded from the ANOVA analysis.
} 
Table 3 Point transfer decision

\begin{tabular}{|c|c|c|c|c|c|}
\hline Source of variation $^{b}$ & SS & $\mathrm{df}$ & MS & $\mathrm{F}$ & $\mathrm{p}^{\mathrm{c}}$ \\
\hline \multicolumn{6}{|l|}{ Between-subjects } \\
\hline Charity & 42.711 & 1 & 42.711 & 0.066 & 0.399 \\
\hline Error & $28,561.402$ & 44 & 649.123 & & \\
\hline \multicolumn{6}{|l|}{ Within-subjects } \\
\hline Control & 607.298 & 1 & 607.298 & 8.239 & 0.003 \\
\hline Charity $\times$ Control & 151.925 & 1 & 151.925 & 2.061 & 0.079 \\
\hline Charity $\times$ Error & 3242.303 & 44 & 73.711 & & \\
\hline
\end{tabular}

Panel B: Wilcoxon Signed-Rank test on points transferred from employee to manager (average from rounds 1 to 20)

\begin{tabular}{llll}
\hline Comparison & d.f & Z-Score & $p$ value $^{\mathrm{c}}$ \\
\hline Control versus non-control charity recipient & 1 & 1.188 & 0.118
\end{tabular}

${ }^{\text {a }}$ The dependent variable is the number of points sent by the employee to the manager

${ }^{\mathrm{b}}$ The within-subjects factor is that employees make a point-transfer decision for when the manager does or does not implement a control (minimum-transfer requirement). The between-subjects factor is the manipulation of the third party as either the charity (PAWS) or an unknown third party

${ }^{c}$ We report one-tailed $p$ values

$p$ value $=0.020$, Table 2 , Panel $\mathrm{B}$ ), whereas the difference in the charitable condition is not statistically significant $(\mathrm{Z}$-score $=1.188, p$ value $=0.118$, Table 3 , Panel B $){ }^{25}$ This result means that the costs of controls are lower when the company engages in charitable giving compared to when

\footnotetext{
${ }^{25}$ When engaging in charitable giving, companies face the challenge in which their employees support a myriad of causes. Employees might identify with different causes to different degrees, and more importantly, preferences for charitable causes might shift over time. To gain insight into the effect of the degree of identification with the charitable cause on the costs of control, we perform a median split of our participant sample in the charity condition by the level of emotional identification with the charity. We compare the costs of control for participants with a high identification level (25.98 vs. 28.43) with those for participants with a low identification level (16.71 vs. 19.41). The difference in the costs of control for high identifiers versus low identifiers is not statistically significant $(2.44$ vs. $2.70, \mathrm{Z}$-score $=0.602, p$ value $=0.630$ ). Furthermore, for the highidentification group versus the low-identification group, we also do not find statistically significant differences in the perception of the control system (16.33 vs $17.83, \mathrm{Z}$-score $=0.685, p$ values $=0.713)$ and the level of trust in the interaction partner (31.42 vs. 29.75, $\mathrm{Z}$-score $=0.954, p$ values $=0.977)$. We also performed correlation analyses between emotional identification, point transfer when controls are present, point transfer when controls are absent, the difference between the two (costs of control), the trust measure, and the perception of the control system. Emotional identification does not correlate with any of these outcome variables (all $p$ values $>0.100$ ). Finally, including identification as a covariate in an ANCOVA with costs of control as the dependent measure and control presence and charitable giving as independent factors does not qualitatively change our main results. In summary, these analyses show that the effect of the degree of identification with the charity does not seem to affect the effect of charitable giving on the costs of control.
}

the company does not engage in charitable giving, which provides support for $\mathrm{H} 1$.

\section{Testing Halo Effects Through a Process Model (H2 and H3)}

Next, we analyze the processes that generate differences in the costs of control between the charity and the non-charity conditions. This section presents a process model that combines our dependent, independent, and process variables and analyzes them in a path analysis model using AMOS statistical software (Fig. 3). Consistent with the proposed halo effects, we expect that charitable giving has a positive effect on the perception of control. We further propose that a more favorable perception of formal control leads to a decrease in the costs of control (measured as the point difference between when controls are present and when controls are absent). In addition, we propose that charitable giving leads to a higher perceived trustworthiness of the manager who makes the control implementation decision. Higher trustworthiness affects the costs of control as an indirect effect through the perception of the actions of the person implementing the controls in such a way that controls are assessed more favorably. All measures indicate that this proposed model is a good fit for the data (Chi-square $=2.493, p$ value $=0.288 ; \mathrm{RMSEA}=0.074 ; \mathrm{CFI}=0.922 ; \mathrm{GFI}=0.972$ ). In this model, our dependent variable (costs of control) is employee participants' point transfers when control is present minus those when control is absent. 
Fig. 3 Proposed process model

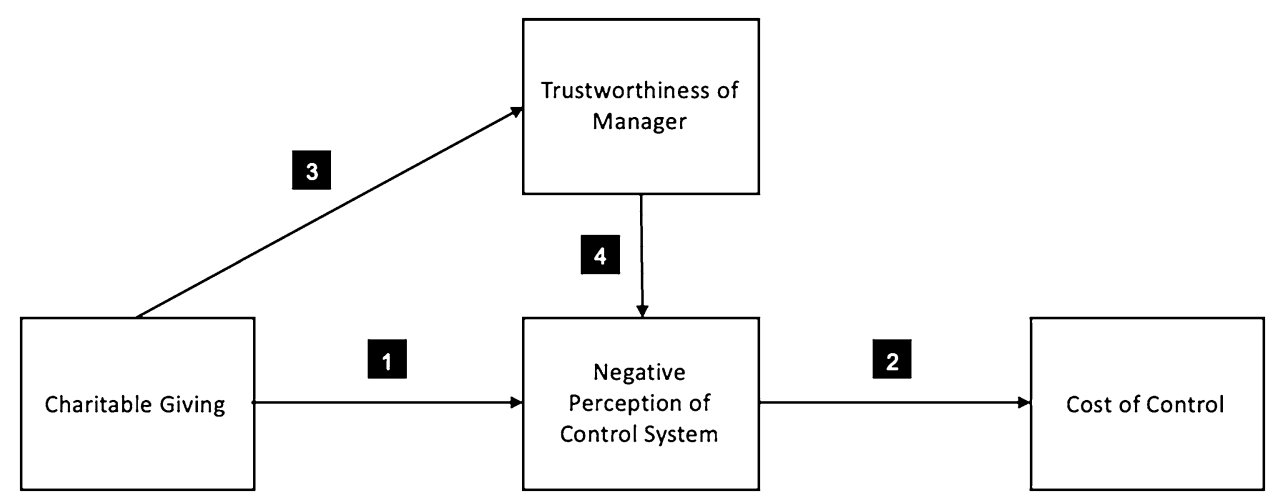

Our path analysis model finds support for the proposed halo effects (Table 4). First, charitable giving leads to a more favorable assessment of formal control (link $1, p$ value $=0.065)$, which supports Hypothesis $2 .{ }^{26} \mathrm{~A}$ more favorable assessment of formal control leads to a decrease in the costs of control (link $2, p$ value $=0.016$ ) .

Second, we find that charitable giving leads to a higher perceived trustworthiness of managers (link $3, p$ value $=0.027$, which supports Hypothesis $3 .^{27}$ The trustworthiness of the manager, in turn, has a negative effect on the perceived negativity of formal control, meaning that a more positive assessment of the manager leads to a less negative perception of controls (link $4, p$ value $=0.041$ ). The indirect effect of the employee perception of the trustworthiness of the manager who makes the decision to implement controls, as exerted through the perception of formal controls, on the costs of control is statistically significant (standardized weight $=-0.084, p$ value $=0.012$ ).

In summary, our findings provide support for the proposed halo effects. Our path analysis model provides

\footnotetext{
26 Table 5, Panel A provides descriptive statistics for the combined measure of the employees' perception of the control system. The mean scores indicate a lower negative perception of the minimum point transfer that the control system enforces in the charity condition compared to when the third-party recipient is unspecified. Table 5, Panel B shows a pairwise comparison of the perception of the control system in the charity condition compared to the non-charity condition. In the charity condition, participants perceive the control system to be less negative compared to when the third-party recipient is unspecified $(\mathrm{Z}$-score $=2.130, p$ value $=0.017$ ). This finding provides additional support for Hypothesis 2.

27 Table 6, Panel A provides descriptive statistics for that measure. In the charity condition, on average, participants perceive the manager participant as more trustworthy compared to when the third-party recipient is unspecified. Table 6, Panel B shows a pairwise comparison of the perceived trustworthiness of the manager as rated by the employee, comparing the charity condition with the non-charity condition. The difference is statistically significant $(\mathrm{Z}$-score $=1.830$, $p$ value $=0.034)$. This finding shows that in the charity condition, employees have a more positive assessment of the manager compared to the non-charity condition, which provides additional support for Hypothesis 3.
}

statistical support for the proposed effect of charitable giving on the perception of formal controls, along with the indirect effect of charitable giving on the perceived trustworthiness of the manager implementing the control and the perception of control. ${ }^{28}$

\section{Supplemental Analysis: Changes Over Time}

Emotions could drive the effect of charitable giving on the costs of control. Emotions are inherently transient; they tend not to persist over long periods of time, particularly in laboratory settings (Isen et al. 1976). While we acknowledge that a 20-round experiment is an imperfect proxy for gauging long-term effects, a significant decrease in employee response to formal control from the early parts of the study to the later part would indicate that the benefit of charitable giving might result from short-lived emotions. We compare the difference in point transfers when control is present versus point transfers when control is absent (costs of control) for the first ten rounds with the difference for the second ten rounds. We find that the costs of control do not differ

\footnotetext{
${ }^{28}$ Support for this process model also helps us rule out other theories that could potentially explain a positive effect of charitable giving on the costs of control, namely, contract theory and indirect reciprocity. According to signaling theory, lower costs of control could result because managers strategically engage in charitable giving (BrownLiburd and Zamora 2015; Brown-Liburd et al. 2018). However, this alternate explanation does not apply in our setting because the manager does not make the decision to donate to charity. Rather, the decision is made by the company and implemented as an automatic point transfer. Hence, we believe a core requirement for signaling theory to apply, which is intentionally sending a signal to reduce uncertainty, is absent. Similarly, indirect reciprocity proposes that cooperation is higher with individuals with a higher reputation. Although our results for perceived trustworthiness could potentially support either theory, our findings regarding the effect of charitable giving on the perception of the control system could not be explained by these alternate theories. However, we acknowledge that in settings with other features, such as managers having a say in the decision to make charitable contributions, other forces that could be explained by signaling theory or indirect reciprocity could explain the behavior by employees, in addition to the halo effects our results show to be present.
} 
Table 4 Process model

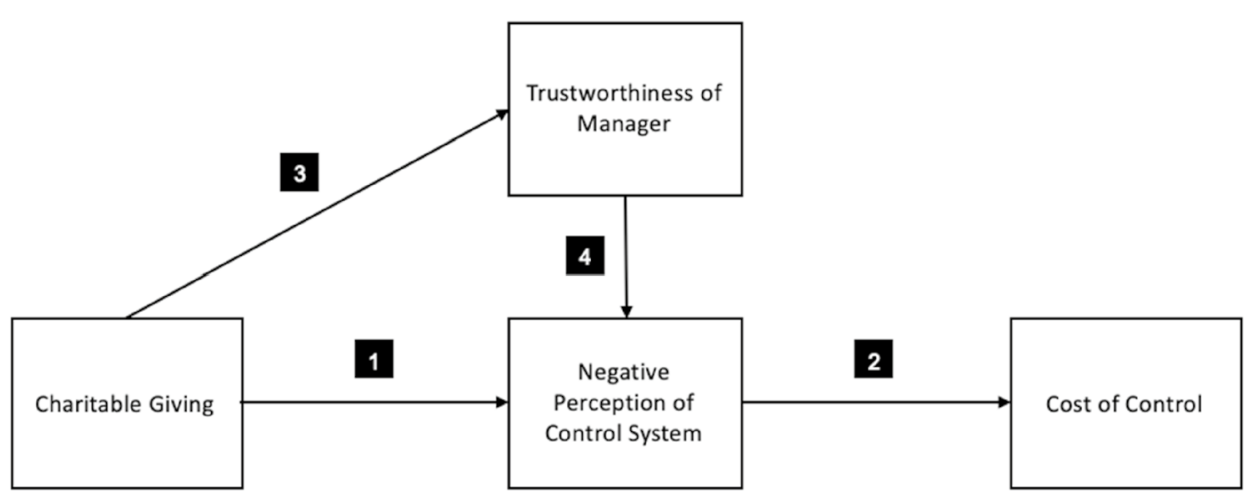

\begin{tabular}{|c|c|c|c|}
\hline$\underset{\#}{\operatorname{Link}}$ & Parameter estimate & $\begin{array}{c}\text { Standardized } \\
\text { estimate }\end{array}$ & p-value ${ }^{b}$ \\
\hline 1 & $\begin{array}{l}\text { Charitable Giving }{ }^{\mathrm{a}} \rightarrow \\
\text { Negative Perception of } \\
\text { Control System }\end{array}$ & -0.224 & 0.065 \\
\hline 2 & $\begin{array}{c}\text { Negative Perception of } \\
\text { Control System } \rightarrow \text { Costs } \\
\text { of Control }\end{array}$ & 0.322 & 0.016 \\
\hline 3 & $\begin{array}{c}\text { Charitable Giving }^{\mathrm{a}} \rightarrow \\
\text { Trustworthiness of } \\
\text { Manager }\end{array}$ & 0.285 & 0.027 \\
\hline 4 & $\begin{array}{c}\text { Trustworthiness of } \\
\text { Manager } \rightarrow \text { Negative } \\
\text { Perception of Control } \\
\text { System }\end{array}$ & -0.260 & 0.041 \\
\hline
\end{tabular}

${ }^{a}$ Charitable giving is manipulated as either the recipient of funds specified as PAWS or an unknown third party

${ }^{\mathrm{b}}$ We report one-tailed $p$ values

over the course of the experiment, either in the full sample $(Z$-score $=0.439, p$ value $=0.660)$ or for only the charity condition $(Z$-score $=0.251, p$ value $=0.802)$.

Based on this analysis, we find no indication that the positive effect of charitable giving on the employee response to formal control is temporary. Together with our process variables, this finding provides assurance that the effect of charitable giving on the costs of control results from a cognitive process with deeper roots than an impulsive emotional reaction.

\section{Conclusion}

This study extends research on how formal controls affect employee behavior by examining the effect of charitable giving on the perception of managers' trustworthiness, the perception of control systems, and the costs of control. We find that charitable giving by a company-even when a manager does not make the decision behind such giving-reduces employees' adverse reactions to a control introduced by a manager. A path analysis model shows that these lower costs of control result from two halo processes. First, charitable giving lowers the costs of control by improving the perception of the control, making it less negative. Second, it acts indirectly by prompting a more positive assessment of the trustworthiness of the manager implementing a control, which has a positive effect on the perception of controls. We further show that the positive effect of corporate giving on employees' responses to formal controls holds across 20 rounds of the experiment. This finding, together with our path analysis model, suggests that the effect of charitable giving on the costs of control results from a cognitive process rather than a short-lived emotional reaction.

Our findings make several contributions to the literature on control systems and charitable giving. Previous literature 
Table 5 Perception of controls

Panel A: Mean (standard deviation) of employee perception of controls ${ }^{\mathrm{a}}$

\begin{tabular}{|c|c|c|}
\hline & $\begin{array}{l}\text { Unspecified recipient } \\
n=22\end{array}$ & $\begin{array}{l}\text { Charity } \\
\text { recipient } \\
n=24\end{array}$ \\
\hline 1. To what extent do you feel that Participant Bs questioned your integrity? ${ }^{\mathrm{b}}$ & $\begin{array}{l}7.05 \\
(2.92)\end{array}$ & $\begin{array}{l}6.17 \\
(2.24)\end{array}$ \\
\hline 2. To what extent do you perceive the minimum-transfer requirement as a sign of distrust? ${ }^{\mathrm{b}}$ & $\begin{array}{l}7.59 \\
(2.38)\end{array}$ & $\begin{array}{l}5.42 \\
(3.30)\end{array}$ \\
\hline 3. To what extent do you consider the minimum-transfer requirement as a restriction on your free will? ${ }^{\mathrm{b}}$ & $\begin{array}{l}6.59 \\
(2.56)\end{array}$ & $\begin{array}{l}5.50 \\
(3.45)\end{array}$ \\
\hline Control Perception Score $(\alpha=0.748)$ & $\begin{array}{l}21.23 \\
(6.76)\end{array}$ & $\begin{array}{l}17.09 \\
(7.04)\end{array}$ \\
\hline \multicolumn{3}{|l|}{ Panel B: Mann-Whitney test on the "control perception score" } \\
\hline Comparison & Z-Score & $p$ value $^{\mathrm{c}}$ \\
\hline Charity recipient versus unknown recipient & 2.130 & 0.017 \\
\hline
\end{tabular}

aThe dependent variable is the employee's perception of the control implementation

${ }^{\mathrm{b}}$ Measured on a 1 to 11 scale

${ }^{\mathrm{c}}$ We report one-tailed $p$ values

Table 6 Trust score of the employee toward the manager

Panel A: Mean (standard deviation) of employee trust of the manager ${ }^{\mathrm{a}}$

\begin{tabular}{|c|c|c|}
\hline & $\begin{array}{l}\text { Unspecified recipient } \\
n=22\end{array}$ & $\begin{array}{l}\text { Charity recipient } \\
n=24\end{array}$ \\
\hline 1. Trustworthy ${ }^{\mathrm{b}}$ & $\begin{array}{l}2.91 \\
(1.41)\end{array}$ & $\begin{array}{l}3.17 \\
(0.82)\end{array}$ \\
\hline 2. Compassionate ${ }^{b}$ & $\begin{array}{l}3.05 \\
(0.95)\end{array}$ & $\begin{array}{l}3.38 \\
(0.88)\end{array}$ \\
\hline 3. Risky to associate with ${ }^{\mathrm{b}, *}$ & $\begin{array}{l}3.77 \\
(1.38)\end{array}$ & $\begin{array}{l}2.79 \\
(1.32)\end{array}$ \\
\hline $\begin{array}{l}\text { 4. I perceive Participant Bs to be individuals who can be trusted to serve the interest of oth- } \\
\text { ers rather than themselves }{ }^{c}\end{array}$ & $\begin{array}{l}3.82 \\
(2.22)\end{array}$ & $\begin{array}{l}4.46 \\
(2.34)\end{array}$ \\
\hline 5. Participant Bs would never try to gain an advantage by deceiving me $\mathrm{e}^{\mathrm{c}}$ & $\begin{array}{l}3.50 \\
(2.45)\end{array}$ & $\begin{array}{l}3.83 \\
(2.18)\end{array}$ \\
\hline 6. I have complete faith in the integrity of Participant $\mathrm{Bs}^{\mathrm{c}}$ & $\begin{array}{l}3.59 \\
(1.74)\end{array}$ & $\begin{array}{l}3.96 \\
(2.07)\end{array}$ \\
\hline $\begin{array}{l}\text { 7. I perceive Participant Bs to be individuals who pursue their own best interest at the } \\
\text { expense of others }{ }^{\mathrm{c}^{*}}\end{array}$ & $\begin{array}{l}5.86 \\
(2.21)\end{array}$ & $\begin{array}{l}5.42 \\
(2.23)\end{array}$ \\
\hline Trust Score $(\alpha=0.662)^{\mathrm{e}}$ & $\begin{array}{l}27.23 \\
(7.10)\end{array}$ & $\begin{array}{l}30.58 \\
(7.27)\end{array}$ \\
\hline
\end{tabular}

Panel B: Mann-Whitney test on the "trust score"

\begin{tabular}{llll}
\hline Comparison & d.f & Z-Score & $p$ value $^{\mathrm{d}}$ \\
\hline Charity recipient versus unknown recipient & 1 & 1.830 & 0.034 \\
\hline
\end{tabular}

*Reverse-coded in the score calculation

'The dependent variable is the employees' perception of the managers' trustworthiness

${ }^{\mathrm{b}}$ Measured on a 1 to 7 scale

${ }^{\mathrm{c}}$ Measured on a 1 to 11 scale

${ }^{\mathrm{d}}$ We report one-tailed $p$ values

${ }^{\mathrm{e}}$ The aggregated trust score is calculated as the sum of items 1 to 7 with the items 3 and 7 reverse-coded 
on the negative effects of control systems does not examine CSR expressed through charitable giving as a mitigating factor. We show that a company that serves a socially beneficial purpose such as charitable giving can substantially reduce the costs of control. Applied to practice, our findings imply that the costs of control might not be as prevalent, at least for companies that serve a beneficial purpose for society, as research suggests.

In addition, our study contributes to the literature on charitable giving as a CSR activity. Previous research has focused on the benefits of CSR from decisions by external stakeholders such as consumers, investors, policymakers, and job seekers. We add to a growing body of research by examining the benefits of corporate giving in terms of the behavior of internal stakeholders (e.g., Aguilera et al. 2007; Rodrigo and Arenas 2008; Hansen et al. 2011; De Roeck and Maon 2018). We add to this research by showing, in a controlled laboratory setting, that corporate giving can lower employee moral hazard and increase employee effort and motivation (Bénabou and Tirole 2010; Balakrishnan et al. 2011; Dijk and Holmen 2017).

Experiments allow us to examine causal relationships in controlled settings, but they require abstracting from reality. This study is not an exception to this tradeoff. First, as with most laboratory experiments, we rely on a limited sample size. Specifically, we have 22 employee participants in the unspecified third-party recipient condition and 24 employee participants in the charitable condition. Compared to the number of individuals affected by controls in real-life settings, this sample size is limited. The statistically insignificant difference in points transferred from the employee to the manager in the charitable giving condition when the manager implements a control compared to the absence of a control could be economically impactful in real life. However, even then, our conclusion that the costs of control are significantly smaller when a company engages in charitable giving would hold.

Additionally, our multi-round experimental setting allows us to examine changes in behavior over time. However, this design comes with the risk of inducing fatigue and demand effects. Additional robustness tests indicate that neither factor appears to bias our results. In addition, our setting provides a direct link between point transfers and charitable giving. This link could potentially limit the applicability of our findings to environments with production functions, where employee effort leads to increases in wealth for companies, which in turn automatically increases charitable giving. Lastly, we did not indicate that we intended to contribute the funds sent to the unspecified third party to a charity in our unknown third-party condition. Thus, our setting differs from a setting in which it is known that money is donated to a charity, though the charity's cause is unspecified.

Our study offers opportunities for further research. More research on the strength of the employees' identification with a charity is warranted. For example, we chose a charity that is easy to identify with, particularly for the young people who participated in the experiment. The empirical question of how the degree of employee identification with a charitable cause affects the positive effects of such giving remains..$^{29}$ On the one hand, employees might nevertheless appreciate the act of philanthropy even when they identify with the charity to a low extent or disagree with the charity's mission. If charitable giving generates positive effects, irrespective of the level of identification, then corporate giving would be greatly simplified, as corporations could commit to a charitable cause for longer periods of time without having to continuously gauge employee identification with charitable causes and incorporate such preferences into their charitable giving approach. Similarly, charities could rely on long-term donors and commit to long-term projects. On the other hand, the positive effect of charitable giving on, for instance, the costs of control could be suppressed with lower levels of employee identification with charitable causes. In the case in which employees oppose the charity's mission, the negative perceptions of a control system could even be amplified. Future research to further examine these relationships between employee identification with a charity and employee positive reactions to charitable giving is warranted. ${ }^{30}$

Notwithstanding any inherent and necessary limitations, we believe that our results provide important implications for practice. For example, our findings inform companies that charitable giving can yield benefits in terms of the behavior of internal stakeholders. In addition, our findings indicate that the implementation of formal controls is not a decision or process that should be considered by itself, but rather, in the context of broader corporate decisions, such as corporate charitable giving, as well as communication with employees about such charitable giving and the ways in which a company contributes to society.

Acknowledgements We would like to thank Alexander Wagner, Jace Garrett (MAS discussant), Margaret Christ, and Khim Kelley. The paper has greatly benefitted from workshop comments at the MAS conference 2018 and the VHB conference 2020.

\footnotetext{
29 This question is important, as research suggests that companies choose charitable causes based on factors such as CEO preferences (Werbel and Carter 2002), the proximity of the charity to company headquarters (Card et al. 2010), or as a means to enhance brand image (Lafferty 2009). Research on including employees' preferences and perspective in such decisions remains scarce (Barman 2007; Breeze and Wiepking 2018).

${ }^{30}$ We present analyses of the effect of identification with PAWS on the positive effect of charitable giving on the costs of control (see footnote 25). Using a small sample, we find that in our setting, the extent of identification does not alter the positive effect of charitable giving on the costs of control. In other words, charitable giving leads to lower costs of control, regardless of the degree of identification with the charity.
} 
Funding Open Access funding enabled and organized by Projekt DEAL.

\section{Compliance with Ethical Standards}

Conflict of interest The authors declare that they have no conflict of interest.

Open Access This article is licensed under a Creative Commons Attribution 4.0 International License, which permits use, sharing, adaptation, distribution and reproduction in any medium or format, as long as you give appropriate credit to the original author(s) and the source, provide a link to the Creative Commons licence, and indicate if changes were made. The images or other third party material in this article are included in the article's Creative Commons licence, unless indicated otherwise in a credit line to the material. If material is not included in the article's Creative Commons licence and your intended use is not permitted by statutory regulation or exceeds the permitted use, you will need to obtain permission directly from the copyright holder. To view a copy of this licence, visit http://creativecommons.org/licenses/by/4.0/.

\section{References}

Aguilera, R. V., Rupp, D. E., Williams, C. A., \& Ganapathi, J. (2007). Putting the $\mathrm{S}$ back in corporate social responsibility: A multilevel theory of social change in organizations. Academy of Management Review, 32(3), 836-863.

Albert, M., Güth, W., Kirchler, E., \& Maciejovsky, B. (2007). Are we nice(r) to nice(r) people?-An experimental analysis. Experimental Economics, 10(1), 53-69.

Aquino, K., \& Reed, I. I. (2002). The self-importance of moral identity. Journal of Personality and Social Psychology, 83(6), 1423.

Ashraf, N., Bohnet, I., \& Piankov, N. (2006). Decomposing trust and trustworthiness. Experimental Economics, 9(3), 193-208.

Balakrishnan, R., Sprinkle, G. B., \& Williamson, M. G. (2011). Contracting benefits of corporate giving: An experimental investigation. The Accounting Review, 86(6), 1887-1907.

Barclay, P. (2004). Trustworthiness and competitive altruism can also solve the "tragedy of the commons." Evolution and Human Behavior, 25(4), 209-220.

Barman, E. (2007). An institutional approach to donor control: From dyadic ties to a field-level analysis. American Journal of Sociology, 112(5), 1416-1457.

Bénabou, R., \& Tirole, J. (2010). Individual and corporate social responsibility. Economica, 77(305), 1-19.

Block, E. S., Glavas, A., Mannor, M. J., \& Erskine, L. (2017). Business for good? An investigation into the strategies firms use to maximize the impact of financial corporate philanthropy on employee attitudes. Journal of Business Ethics, 146(1), 167-183.

Bol, J. C., \& Smith, S. D. (2011). Spillover effects in subjective performance evaluation: Bias and the asymmetric influence of controllability. The Accounting Review, 86(4), 1213-1230.

Breeze, B., \& Wiepking, P. (2018). Different Drivers: Exploring employee involvement in corporate philanthropy. Journal of Business Ethics, 1-15.

Brown-Liburd, H., Cohen, J., \& Zamora, V. L. (2018). CSR disclosure items used as fairness heuristics in the investment decision. Journal of Business Ethics, 152(1), 275-289.

Brown-Liburd, H., \& Zamora, V. L. (2015). The role of corporate social responsibility (CSR) assurance in investors' judgments when managerial pay is explicitly tied to CSR performance. Auditing: A Journal of Practice \& Theory, 34(1), 75-96.

Card, D., Hallock, K. F., \& Moretti, E. (2010). The geography of giving: The effect of corporate headquarters on local charities. Journal of Public Economics, 94(3-4), 222-234.

Chandon, P., \& Wansink, B. (2007). The biasing health halos of fastfood restaurant health claims: Lower calorie estimates and higher side-dish consumption intentions. Journal of Consumer Research, 34(3), 301-314.

Chaudhuri, A., \& Gangadharan, L. (2007). An experimental analysis of trust and trustworthiness. Southern Economic Journal, 73, 959-985.

Chernev, A., \& Blair, S. (2015). Doing well by doing good: The benevolent halo of corporate social responsibility. Journal of Consumer Research, 41(6), 1412-1425.

Christ, M. H. (2013). An experimental investigation of the interactions among intentions, reciprocity, and control. Journal of Management Accounting Research, 25(1), 169-197.

Christ, M. H., Sedatole, K. L., \& Towry, K. L. (2012). Sticks and carrots: The effect of contract frame on effort in incomplete contracts. The Accounting Review, 87(6), 1913-1938.

Christ, M. H., Sedatole, K. L., Towry, K. L., \& Thomas, M. A. (2008). When formal controls undermine trust and cooperation. Strategic Finance, 89(7), 39.

Coletti, A. L., Sedatole, K. L., \& Towry, K. L. (2005). The effect of control systems on trust and cooperation in collaborative environments. The Accounting Review, 80(2), 477-500.

De Roeck, K., \& Maon, F. (2018). Building the theoretical puzzle of employees' reactions to corporate social responsibility: An integrative conceptual framework and research agenda. Journal of Business Ethics, 149(3), 609-625.

Dijk, O., \& Holmén, M. (2017). Charity, incentives, and performance. Journal of Behavioral and Experimental Economics, 66, 119-128.

Dion, K., Berscheid, E., \& Walster, E. (1972). What is beautiful is good. Journal of Personality and Social Psychology, 24(3), 285.

Duarte, N. T., Goodson, J. R., \& Klich, N. R. (1994). Effects of dyadic quality and duration on performance appraisal. Academy of Management Journal, 37(3), 499-521.

El Ghoul, S., Guedhami, O., Kwok, C. C., \& Mishra, D. R. (2011). Does corporate social responsibility affect the cost of capital? Journal of Banking and Finance, 35(9), 2388-2406.

Falk, A., \& Kosfeld, M. (2006). The hidden costs of control. The American Economic Review, 96(5), 1611-1630.

Fehrler, S., \& Przepiorka, W. (2013). Charitable giving as a signal of trustworthiness: Disentangling the signaling benefits of altruistic acts. Evolution and Human Behavior, 34(2), 139-145.

Fischbacher, U. (2007). z-Tree: Zurich toolbox for ready-made economic experiments. Experimental Economics, 10(2), 171-178.

Fischbacher, U., Gächter, S., \& Fehr, E. (2001). Are people conditionally cooperative? Evidence from a public goods experiment. Economics Letters, 71(3), 397-404.

Frey, B. S. (1993). Does monitoring increase work effort? The rivalry with trust and loyalty. Economic Inquiry, 31(4), 663-670.

Greening, D. W., \& Turban, D. B. (2000). Corporate social performance as a competitive advantage in attracting a quality workforce. Business \& Society, 39(3), 254-280.

Hansen, S. D., Dunford, B. B., Boss, A. D., Boss, R. W., \& Angermeier, I. (2011). Corporate social responsibility and the benefits of employee trust: A cross-disciplinary perspective. Journal of Business Ethics, 102(1), 29-45.

Huang, X., \& Watson, L. (2015). Corporate social responsibility research in accounting. Journal of Accounting Literature, 34, $1-16$.

Isen, A. M., Clark, M., \& Schwartz, M. F. (1976). Duration of the effect of good mood on helping: "Footprints on the sands of time." Journal of Personality and Social Psychology, 34(3), 385. 
Kachelmeier, S. J., Thornock, T. A., \& Williamson, M. G. (2016). Communicated values as informal controls: Promoting quality while undermining productivity? Contemporary Accounting Research, 33, 1411-1434.

Kuang, X., \& Moser, D. V. (2009). Reciprocity and the effectiveness of optimal agency contracts. The Accounting Review, 84(5), 1671-1694.

Lafferty, B. A. (2009). Selecting the right cause partners for the right reasons: The role of importance and fit in cause-brand alliances. Psychology \& Marketing, 26(4), 359-382.

Martin, P. R., \& Moser, D. V. (2016). Managers' green investment disclosures and investors' reaction. Journal of Accounting and Economics, 61(1), 239-254.

McNeil, K., Newman, I., \& Kelly, F. J. (1996). Testing research hypotheses with the general linear model. Carbondale, IL: Southern Illinois University Press.

Merchant, K. A., \& Van der Stede, W. A. (2017). Management control systems (4th ed.). Essex, UK: Prentice Hall.

Moser, D. V., \& Martin, P. R. (2012). A broader perspective on corporate social responsibility research in accounting. The Accounting Review, 87(3), 797-806.

Nisbett, R. E., \& Wilson, T. D. (1977). The halo effect: Evidence for unconscious alteration of judgments. Journal of Personality and Social Psychology, 35(4), 250.

O'Donnell, E., \& Schultz, J. J., Jr. (2005). The halo effect in business risk audits: Can strategic risk assessment bias auditor judgment about accounting details? The Accounting Review, 80(3), 921-939.

Peloza, J., \& Shang, J. (2011). How can corporate social responsibility activities create value for stakeholders? A systematic review. Journal of the Academy of Marketing Science, 39(1), 117-135.
Rodrigo, P., \& Arenas, D. (2008). Do employees care about CSR programs? A typology of employees according to their attitudes. Journal of Business Ethics, 83(2), 265-283.

Schnedler, W., \& Vadovic, R. (2011). Legitimacy of control. Journal of Economics and Management Strategy, 20(4), 985-1009.

Sen, S., \& Bhattacharya, C. B. (2001). Does doing good always lead to doing better? Consumer reactions to corporate social responsibility. Journal of Marketing Research, 38(2), 225-243.

Tan, H. T., \& Jamal, K. (2001). Do auditors objectively evaluate their subordinates' work? The Accounting Review, 76(1), 99-110.

Thorndike, E. L. (1920). A constant error in psychological ratings. Journal of Applied Psychology, 4(1), 25-29.

Van Lange, P. A., De Bruin, E., Otten, W., \& Joireman, J. A. (1997). Development of prosocial, individualistic, and competitive orientations: Theory and preliminary evidence. Journal of Personality and Social Psychology, 73(4), 733.

von Siemens, F. A. (2013). Intention-based reciprocity and the hidden costs of control. Journal of Economic Behavior and Organization, 92, 55-65.

Werbel, J. D., \& Carter, S. M. (2002). The CEO's influence on corporate foundation giving. Journal of Business Ethics, 40(1), 47-60.

Ziegelmeyer, A., Schmelz, K., \& Ploner, M. (2012). Hidden costs of control: Four repetitions and an extension. Experimental Economics, 15(2), 323-340.

Publisher's Note Springer Nature remains neutral with regard to jurisdictional claims in published maps and institutional affiliations. 